\title{
Product Market Competition Policy and Technological Performance
}

\author{
Stephen Martin ${ }^{\infty}$ \\ Centre for Industrial E conomics \\ Institute of E conomics \\ University of Copenhagen \\ Studiestaede 6 \\ 1455 Copenhagen K Denmark \\ smart@econ.ku.dk
}

February 1998

\begin{abstract}
A bstract
Stricter competition policy reduces expected payoxs before and after innovation, but reduces pre-innovation payoxs relatively more than postinnovation payoxs, and therefore increases the equilibrium level of $R \& D$ activity: tough product-market competition policy stimulates innovation. There is an inverted- $U$ relationship between competition policy and expected welfare. The model also permits analysis of the exect of $R \& D$ spillovers and of alternative $R \& D$ cooperation regimes on expected welfare, on $R \& D$ exorts, and on the expected time to discovery of a cost-saving innovation.
\end{abstract}

\footnotetext{
I am grateful to seminar participants at the anuary 1998 meetings of the Industrial Organization Society and at BETA, Université L ouis Pasteur and to Paul Geroski for useful comments. Responsibility for errors is my own.
} 


\section{Contents}

1 Introduction ........................ 3

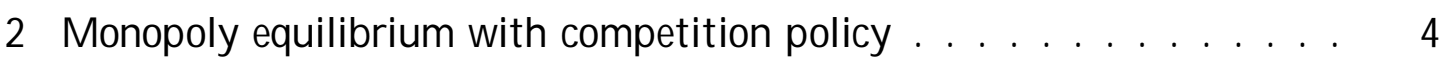

2.1 The market . . . . . . . . . . . . . . . . . . 4

2.2 Modeling competition policy . . . . . . . . . . . . . . . 5

2.3 Competition policy and static monopoly payoxs . . . . . . . . 6

2.3 .1 Example.................... 8

3 Competition Policy and Innovation . . . . . . . . . . . 12

3.1 Monopoly . . . . . . . . . . . . . . . . . . . . 12

3.1.1 Racing for cost-saving innovation . . . . . . . . . . . . 12

3.1.2 Comparative statics with respect to $\mathrm{g} \ldots \ldots \ldots \ldots$

3.2 Duopoly . . . . . . . . . . . . . . . . . . . . . . . . . . . . . 18

3.2 .1 Spillovers . . . . . . . . . . . . . . . . . . . . 18

3.2 .2 Noncooperative $R \& D \ldots \ldots \ldots$

3.2 .3 Operating Entity J oint Venture . . . . . . . . . . . . . 19

3.2 .4 Secretariat J oint Venture . . . . . . . . . . . . . . . . . . . . . 19

3.2 .5 Results . . . . . . . . . . . . . . . . . . . . . . . . . . . . . 19

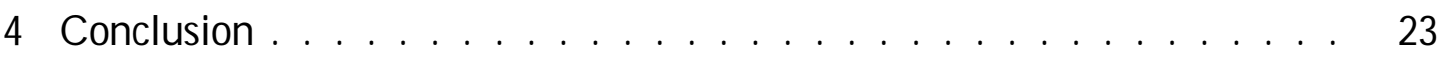

5 Appendix: proof of Theorem $2 \ldots \ldots \ldots \ldots \ldots$

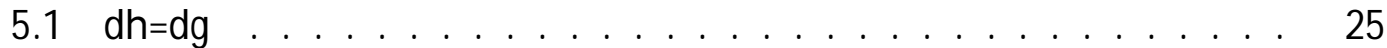

5.2 Comparative statics, post-innovation market . . . . . . . . 27

5.3 Comparative statics, preinnovation market . . . . . . . . . . . 29

6 References . . . . . . . . . . . . . . . . . . . . . . . . 32 
Too much of anything ... isn't necessarily a good thing.

The Trouble with Tribbles.

\section{Introduction}

A large literature examines the impact of $R \& D$ cooperation on technological performance. ${ }^{1}$ In Martin (1996), I show that $R \& D$ cooperation makes it more likely that tacit collusion will be an equilibrium strategy. Here I reverse the direction of causality and investigate the impact of product-market competition policy on technological performance.

In a market system, ...rms invest in new technology and new product development because of the pro.t. they expect to earn after discovery and development. More precisely, a ..rm's incentive to invest in research and development depends on the dixerence between the pro..t it earns before innovation and the pro..t it expects to earn after innovation. ${ }^{2}$

Competition or antitrust policy exposes ..rms to the possibility of ..nes and injunctions if they engage in prohibited conduct. ${ }^{3}$ But the proscriptions of competition law will not be binding constraints unless the probability that violations will be detected is suc ciently high and the penalties that follow conviction are suc ciently great. In practice, neither of these conditions is likely to be met, with the result that the exect of competition policy will be to deter and ameliorate the condemned behavior, not to completely prevent it.

Thus competition policy typically prohibits naked collusion, which nonetheless occurs. Colluding ..rms may think that with a certain probability, their actions will not come to light; or if their actions do come to light, that with a certain probability authorities will not meet the standards of proof laid down by the courts; or that in contrary states of the world, any ...nes eventually imposed are likely to be small relative to collusive pro..ts.

Pro..t-maximizing ..rms will alter their behavior to take expected antitrust penalties into account. Colluding ..rms, for example, may raise price above the noncooperative equilibrium level of a one-shot game, ${ }^{4}$ but deliberately hold price

\footnotetext{
${ }^{1}$ For contributions and references to this literature, see Suzumura and Goto (1997), M eißner and Markl (1997), M artin (1997), and J orde and Teece (1997).

${ }^{2}$ See the literature that follows from A rrow (1962), in particular Gilbert and Newbery (1982, 1984) and Reinganum (1983).

${ }^{3}$ In some circumstances, individuals responsible for decisions to infringe competition rules open themselves up to the possibility of criminal penalties, including imprisonment. Such penalties do occur, but they are exceptional, and are not modelled here.

${ }^{4} \mathrm{Or}$ "a noncooperative equilibrium level of a one-shot game," if there are multiple equilibria.
} 
below the joint-pro..t-maximizing level, to reduce the probability of attracting the attention of enforcement agencies. ${ }^{5}$

This argument suggests a model of antitrust-enforcement limiting behavior on the part of ..rms, and implies that product-market competition policy will reduce pro..tability both before and after innovation. This means that product-market competition policy will axect ..rms' incentives to invest in innovation.

In the model of competition policy that is developed here, stricter competition policy reduces expected payoas before and after innovation, but reduces pre-innovation payous relatively more than post-innovation payoxs, and therefore increases the equilibrium level of $R \& D$ activity. Tough product-market competition policy stimulates innovation.

There is, however, an inverted-U relationship between competition policy and expected welfare. Making competition policy tougher always promotes innovation; it increases welfare up to a certain point, beyond which decreasing returns set in and welfare begins to decline.

The model also yields insights into the exect of $R \& D$ spillovers on expected welfare, on $R \& D$ exorts, and on the expected time to discovery of a cost-saving innovation.

\section{M onopoly equilibrium with competition policy}

\subsection{The market}

Write the equation of the inverse demand curve as

$$
p=p(q)+"
$$

I assume that expected demand $p(q)$ is downward sloping and otherwise well behaved.

The error term " has continuous and dixerentiable density function ${ }^{6} \mathrm{f}($ "), with mean 0 and variance $3 / 2$.

The density function is de..ned over the range

$$
\text { ". " . +; }
$$

where

$$
\text { " }<0<* .1 \text { : }
$$

\footnotetext{
5 In both Trenton Potteries and the electrical equipment conspiracies of the 1950s, the enforcement authorities' attention was brought to the oxending conduct, in the ..rst instance, by customers whose suspicions were aroused by prices that they regarded as excessive.

${ }^{6}$ For an elaboration of the model with linear inverse demand and a uniform distribution of ", see M artin (1998).
} 
There is always some range of prices over which demand is positive:

$$
p(0)+{ }_{-}>0
$$

\subsection{M odeling competition policy}

Competition authorities have limited resources and imperfect information. Imperfect information manifests itself in two ways that are central for the administration of competition policy.

First, imperfect information axects the competition authority's decisions about the allocation of enforcement resources. The competition authority does not directly observe ..rm conduct. It observes the market outcome - here, the realized price. The realized price is in $\neq$ uenced but not completely determined by the ..rm's actions. ${ }^{7}$

To model the competition authority's decision-making process, I suppose that it sets an industry-speci..c threshold price $\mathrm{g}$. If the realized price rises above $\mathrm{g}$, the competition authority investigates the industry. Investigation means that the competition authority devotes some resources to acquiring additional information about the industry, after which it either decides to prosecute ..rms in the industry for violating the law, or it lets the matter drop. ${ }^{8}$

It is realistic to suppose that competition authorities have imperfect information about ..rm conduct, that they monitor industry conditions, and then they decide whether or not to examine a particular industry in detail based on what they observe. The speci..cation that the competition authority considers a single variable when it makes its investigation decision is used for simplicity - in practice, a vector of variables would be observed.

The other way in which imperfect information axects the working of competition policy regards the decision to prosecute and the outcome of such a prosecution, if it should occur. ${ }^{9}$ A high realized price may rełect a large value of " or it may rełect the exercise of monopoly power. If the competition authority investigates an industry, it might conclude that the high observed price is not due to the exercise of market power. Alternatively, it might decide that the high observed

\footnotetext{
${ }^{7}$ In this sense the competition authority and the ..rm stand in a principal-agent relationship, with the competition authority as principal.

${ }^{8}$ In this paper, $g$ is treated as a parameter under the control of the competition authority. Ongoing research examines the competition authority's problem of setting threshold prices when it monitors several industries subject to an overall budget constraint.

${ }^{9}$ B esanko and Spulber (1989) present a model of competition policy with imperfect information that has much in common with models of limit pricing: the competition authority knows that production cost is high or low, but it does not know which. This approach does not allow for uncertainty about the functioning of the legal system.
} 
price is due to the legal exercise of market power. Competition policy typically does not prohibit the exercise of market power as such; what it prohibits is strategic behavior aimed at acquiring or maintaining a position of market power ${ }^{10}$ that is thought to infringe the rules of acceptable business behavior in some way. In either case, a high realized price would trigger an investigation but not result in any liability for the ..rm.

But this is not the only uncertain element of the enforcement process. The competition authority may institute a legal proceeding against the incumbent, but it may not prevail. The competition authority may fail because it is found not to have respected the legal rights of the ..rm. It may fail because it is not able to meet the standards of proof laid down by the letter or interpretation of the law. It may fail because competition law conficts with some other branch of the law and courts resolve the confict against the application of competition law. ${ }^{11}$

From the point of view of ..rms, all these factors make it uncertain whether an antitrust ..ne would be levied, if a high realized price should trigger an investigation. To capture all of this uncertainty about the result of an investigation, I suppose there is a parameter ${ }^{\circ}$, which is common knowledge, that is the probability of investigation, legal challenge, and conviction if price rises above the enforcement threshold $\mathrm{g}$. If the ...rm is found to have oxended the provisions of competition law, it pays a ..ne F. The expected ..ne in the event that an investigation is undertaken - if price rises above $\mathrm{g}-$ is ${ }^{\circ} \mathrm{F} . .^{12}$

\subsection{Competition policy and static monopoly payous}

Given the threshold price g and the distribution of ", a monopolist's instantaneous expected payoo when unit cost is $\mathrm{c}$ is

$$
1 / 4 q ; c ; g)=[p(q) ; \quad c] q i^{\circ} F_{g i p(q)}^{Z} f(") d^{\prime \prime}
$$

The ..rst term on the right is pro..t from the sale of q units of output. The second is the expected value of antitrust ...nes. The lower limit of the integral,

\footnotetext{
${ }^{10}$ Under the terminology "monopolization," "conspiracy to monopolize," "abuse of a dominant position," or "collusion." N ote that collusive outcomes reached through genuinely noncooperative behavior typically do not violate competition policy.

${ }^{11}$ For example, it might have been held that U.S. antitrust law applied to OPEC collusion in the 1970s. In the event, the decision was that foreign policy considerations ruled this out; see Grossack (1986).

${ }^{12}$ It would be possible to endogenize ${ }^{\circ} \mathrm{F}$, by making it a function of the levels of resources devoted to prosecution and to defense, or of some index of the severity of the oxense. But both - and $\mathrm{F}$ are likely to depend in part on the received standards of the legal system, in ways that the legislature and the competition authority can inłuence but not completely control. In U.S. antitrust, the elaboration of the concept of "antitrust injury" is an example. (For evolutionary views of the development of the common law, see Rubin, 1977 and Priest, 1977.)
} 
$g$ i $p(q)$, is the critical value of the random element of demand, given output and the implied expected price chosen by the ..rm. If the realized value of " exceeds g i $p(q)$, the observed price exceeds the threshold level and investigation takes place.

In the second term on the right,

$$
i(g)=\operatorname{Pr}[p(q)+", g]=\operatorname{Pr}[", g i p(q)]={ }_{g i p(q)}^{z} f(") d^{\prime \prime}
$$

is the probability that the competition authority undertakes an investigation. It depends on the threshold price $g$ and on output $q$. A low threshold price indicates a strict competition policy, a high threshold price represents a lenient competition policy.

A tougher competition policy (lower g) increases the probability of investigation, all else equal:

$$
\frac{@}{@ g}=\text { i } f[g \text { i } p(q)]<0:
$$

I will assume that there are decreasing returns to lowering the investigation threshold, in the sense that

$$
\left.\frac{\varrho^{2} i}{\varrho^{2}}=; f q g \text { i } p(q)\right]>0:
$$

There are positive but decreasing returns to deterring the exercise of monopoly power.

The ..rst-order condition to maximize $1 / 4$ c) is ${ }^{13}$

$$
\frac{@ / 4}{@ q}=p(q) ; \quad c+q \frac{d p}{d q} i^{\circ} F f[g ; p(q)] \frac{d p}{d q} ; 0
$$

It follows that the pro..t-maximizing ..rm selects an output that makes marginal revenue less than marginal production cost,

$$
p(q)+q \frac{d p}{d q}=c+{ }^{\circ} F f[g ; p(q)] \frac{d p}{d q}<c
$$

The ..rm expands output above the unconstrained monopoly level to reduce the probability of an antitrust investigation.

\footnotetext{
${ }^{13} \mathrm{~T}$ he second-order suф cient condition for pro..t maximization is

$$
\frac{\bigotimes^{1} 1 / 4}{@^{2}}=2 \frac{d p}{d q} i^{\circ} F f^{0} \frac{d p}{d q}^{\eta_{2}}+\left(q i^{\circ} F f\right) \frac{d^{2} p}{d q^{2}}<0:
$$
}

This is satis..ed for linear demand, and is henceforth assumed. 
Now turn to the question of comparative statics with respect to the threshold price. Dixerentiating the ..rst-order condition with respect to $\mathrm{g}$,

$$
\frac{@^{2} 1 / 4 @ q}{q^{2}} \frac{@^{2} 1 / 4}{@ 9 @ q}=0:
$$

Dixerentiating (2.9) with respect to $g$ and noting that (2.8) implies $f^{0}<0$ gives

Hence

$$
\frac{@^{2} 1 / 4}{@ @ q}=i^{\circ} \mathrm{Ff} 90^{0}<0
$$

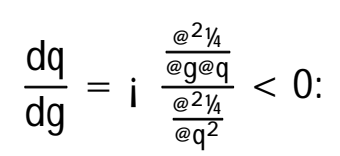

The denominator on the right is negative by the second-order condition for pro.t maximization. Hence lowering the investigation threshold $g$ induces greater equilibrium output. ${ }^{14}$

Regarding the comparative static impact of a change in $\mathrm{g}$ on the ..rm's equilibrium payox,

$$
\frac{d^{1 / 4}}{d g}=\frac{@ / 4}{@ q} \frac{d q}{d g}+\frac{@ / 4}{@ g}={ }^{\circ} F f[g ; \quad p(q)]>0
$$

(making use of the envelope theorem). Tougher competition policy (a lower investigation threshold g) lowers equilibrium pro..t.

\subsubsection{Example}

M onopoly Consider a market with linear inverse demand curve

$$
\mathrm{p}=110 \mathrm{i} \mathrm{Q}+"
$$

Let marginal cost be constant, 10 per unit, and suppose there are no ..xed costs. If the industry were perfectly competitive, long-run equilibrium price would be 10.

Let the density of the random part of demand be exponential, ${ }^{15}$

$$
f(")=\frac{1}{10} \exp _{i} \frac{\mu^{\prime \prime}+10^{\prime}}{10}
$$

\footnotetext{
${ }^{14} \mathrm{O}$ ne can also show that an increase in ${ }^{\circ} \mathrm{F}$ increases equilibrium output.

${ }^{15} \mathrm{~A}$ truncated normal distribution would yield similar results, except that such a case would always have equilibrium $g_{i} p>0$. In this sense, the exponential speci..cation implies a weak competition policy.
} 


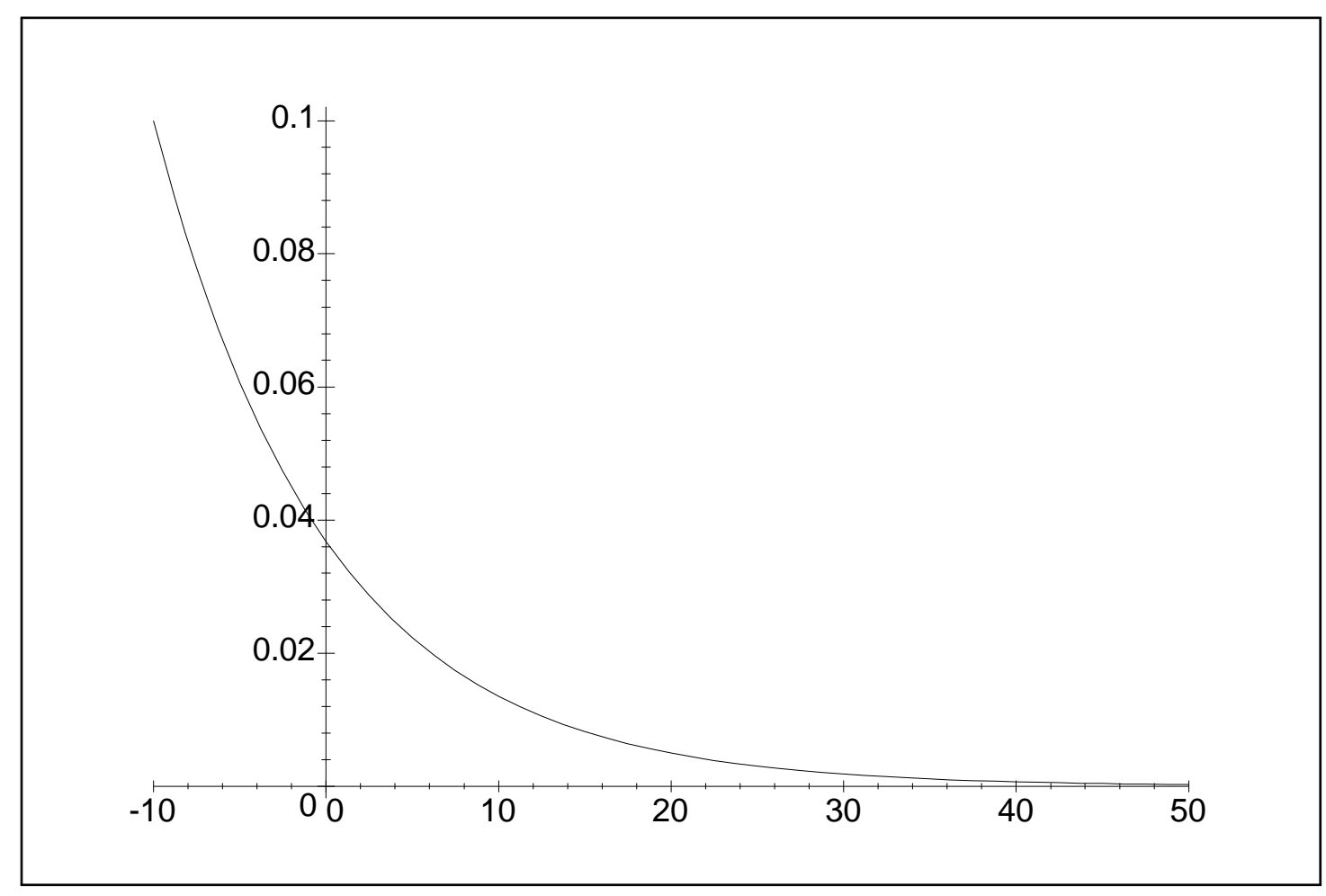

Figure 2.1: Exponential density function, $f(")=\frac{1}{10} \exp i^{3} \frac{n+10}{10}$

This has range ( $\mathrm{i}$ 10; 1 ) (see Figure 2.1). " has mean 0 and variance $3 / 4=100$. For this density function, it is more likely that " will fall in a range of modestly negative values than in a higher range of identical length.

Table 3.4 reports the main characteristics of monopoly equilibrium without competition policy and for threshold prices ranging from 70 to 10 . Without competition policy, monopoly pro..t is 2500 per time period. The ..gures reported in Table 2.1 are calculated for ${ }^{\circ} \mathrm{F}=1000$. This is $40 \%$ of the no-competition policy payox.

Here and in what follows, I measure expected net social welfare as the sum of expected economic pro..t and expected consumers' surplus, ${ }^{16}$ on the ground that from a normative point of view this is what an impartial competition authority would maximize. ${ }^{17}$

\footnotetext{
${ }^{16} \mathrm{~W}$ hen the discussion moves to innovation, these are measured in terms of expected present discounted values.

${ }^{17}$ T he expected value of ..nes is a transfer from ..rms to the competition authority, and thus not lost to society, enforcement costs must be set against such transfers. Proper consideration of net enforcement cost requires a model of the behavior of a competition authority that allocates
} 


\begin{tabular}{|c|c|c|c|c|c|c|}
\hline $\mathrm{g}$ & $\mathrm{q}_{\mathrm{m}}$ & $\mathrm{p}_{\mathrm{m}}$ & $i$ & $1 / 4 \mathrm{~m}$ & $\mathrm{CS}$ & $1 / \mathrm{m}_{\mathrm{m}}+\mathrm{CS}$ \\
\hline No $\mathrm{cp}$ & $50: 00$ & $60: 00$ & $\mathrm{na}$ & $2500: 0$ & $1250: 0$ & $3750: 0$ \\
\hline 70 & $54: 37$ & $55: 63$ & $0: 087$ & $2393: 5$ & $1478: 1$ & $3871: 6$ \\
\hline 65 & $56: 08$ & $53: 92$ & $0: 122$ & $2341: 6$ & $1572: 3$ & $3913: 9$ \\
\hline 60 & $58: 15$ & $51: 85$ & $0: 163$ & $2270: 7$ & $1690: 5$ & $3961: 2$ \\
\hline 55 & $60: 56$ & $49: 45$ & $0: 211$ & $2177: 5$ & $1833: 5$ & $4011: 0$ \\
\hline 50 & $63: 27$ & $46: 73$ & $0: 265$ & $2058: 6$ & $2001: 4$ & $4060: 0$ \\
\hline 45 & $66: 24$ & $43: 76$ & $0: 392$ & $1911: 3$ & $2194: 1$ & $4105: 4$ \\
\hline 40 & $69: 45$ & $40: 56$ & $0: 389$ & $1733: 0$ & $2411: 3$ & $4144: 3$ \\
\hline 35 & $72: 84$ & $37: 16$ & $0: 457$ & $1521: 8$ & $2652: 6$ & $4174: 4$ \\
\hline 30 & $76: 39$ & $33: 61$ & $0: 528$ & $1275: 7$ & $2917: 7$ & $4193: 4$ \\
\hline 25 & $80: 08$ & $29: 92$ & $0: 602$ & $993: 5$ & $3206: 5$ & $4200: 0$ \\
\hline 20 & $83: 89$ & $26: 11$ & $0: 678$ & $673: 7$ & $3518: 7$ & $4192: 4$ \\
\hline 15 & $87: 80$ & $22: 20$ & $0: 756$ & $315: 4$ & $3854: 2$ & $4169: 6$ \\
\hline 10 & $91: 79$ & $18: 21$ & $0: 836$ & $\mathrm{i} 82: 5$ & $4213: 0$ & $4130: 5$ \\
\hline
\end{tabular}

Table 2.1: Static Monopoly Market Performance, Alternative Investigation Thresholds

$$
\text { Notes: } p=110 \text {; } Q, c=10,{ }^{\circ}=1=2, F=2000,3 / 4=10 \text {. }
$$

$\mathrm{g}=70$ is a relatively high threshold price, one standard deviation above the no-competition policy monopoly price. It results in a relatively small probability of investigation - $8.7 \%$ - but also an $8.7 \%$ expansion in output and a 3.2\% increase in net social welfare, compared with the no-competition policy case.

As the threshold price falls, output and consumers' surplus rise and economic pro..t falls. For high and intermediate values of $g(g, 45)$, the expected price is below the threshold price. For lower values of $g$, the expected price is above the threshold price.

Despite the increase in output, the equilibrium probability of investigation rises as $\mathrm{g}$ falls. When $\mathrm{g}$ falls, the comparative static response of the monopolist is to expand output, but the monopolist does not expand output so much that the direct exect of a lower threshold price on the probability of investigation is neutralized or reversed.

Even for low threshold prices, when the equilibrium expected price is above $\mathrm{g}$, the probability of investigation is less than 1: there is always some chance that a large negative " will push the realized price below the investigation threshold.

There is an inverted- $U$ relationship between $g$ and net social welfare: beyond a certain point ( $1 / 425$ for this example), further increases in the severity of

scarce enforcement resources across several industries, and is the subject of ongoing research. 
competition policy reduce net social welfare. For threshold prices at low levels, the reductions in expected pro..t (after allowing for expected ..nes) that follow from further reductions in g more then oxset further gains in consumers' surplus. This is a consequence of the assumption that there are decreasing returns to lowering the investigation threshold.

Oligopoly Qualitatively similar results obtain for noncooperative oligopoly. Table 2.2 gives numerical results for the market of the monopoly example when there are two quantity-setting ..rms and each ..rm noncooperatively maximizes its own expected payou,

$$
1 / 4\left(q_{1} ; q_{2} ; c ; g\right)=\left[p\left(q_{1}+q_{2}\right) \text { i } c\right] q_{i i} i^{\frac{1}{2}}{ }^{\circ} F_{\text {gi } p}^{Z} f(") d^{\prime \prime}
$$

The ..nal term on the right implies that if there is a successful prosecution, each ..rm expects to pay one-half of the resulting ...ne. ${ }^{18}$ This speci..cation is appropriate for joint oxenses against competition policy, such as tacit collusion or joint strategic entry deterrence. It would not be appropriate for single..rm violations of competition policy, such as (for example) abuse of a dominant position.

As in Table 2.1, output, the probability of investigation, and consumers' surplus all rise as competition policy becomes stricter - as g falls. E conomic pro..t falls as $g$ falls. Once again, there is an inverted-U relation between $g$ and net social welfare. A moderately strict competition policy improves net social welfare.

The size of the impact of competition policy on market performance is less for duopoly than for monopoly (without competition policy, expected net social welfare is 4444.4; maximum expected net social welfare with competition policy is approximately 4449.9 , for $g^{1 / 455)}$. This is a consequence of the improvement in market performance when there are two ..rms rather than one.

\footnotetext{
${ }^{18} \mathrm{~A}$ nticipating situations in which ..rms have dixerent unit costs and therefore dixerent equilibrium market shares, one might wish to investigate a model in which a ..rm expects to pay a fraction of the expected ..ne equal to its market share. Such a speci..cation would complicate ..rst-order conditions, compared with equation (2.17); it would not change equilibrium total output, and is not examined here.
} 


\begin{tabular}{|c|c|c|c|c|c|c|}
\hline $\mathrm{g}$ & $\mathrm{q}_{\mathrm{N}}$ & $\mathrm{p}_{\mathrm{N}}$ & $i$ & \multicolumn{1}{c|}{$/ \mathrm{N}$} & $\mathrm{CS}$ & $2^{1 / 4} \mathrm{~N}+\mathrm{CS}$ \\
\hline No CP & $33: 33$ & $43: 33$ & $\mathrm{na}$ & $1111: 1$ & $2222: 2$ & $4444: 4$ \\
\hline 70 & $33: 73$ & $42: 55$ & $0: 024$ & $1085: 9$ & $2275: 0$ & $4446: 8$ \\
\hline 65 & $33: 95$ & $42: 09$ & $0: 037$ & $1071: 0$ & $2305: 7$ & $4447: 8$ \\
\hline 60 & $34: 29$ & $41: 42$ & $0: 057$ & $1048: 7$ & $2351: 6$ & $4449: 0$ \\
\hline 55 & $34: 77$ & $40: 47$ & $0: 086$ & $1016: 2$ & $2417: 5$ & $4449: 9$ \\
\hline 50 & $35: 41$ & $39: 18$ & $0: 125$ & $970: 9$ & $2507: 9$ & $4449: 7$ \\
\hline 45 & $36: 24$ & $37: 53$ & $0: 174$ & $910: 5$ & $2626: 9$ & $4446: 9$ \\
\hline 40 & $37: 25$ & $35: 51$ & $0: 235$ & $832: 8$ & $2774: 5$ & $4439: 9$ \\
\hline 35 & $38: 43$ & $33: 15$ & $0: 306$ & $736: 6$ & $2953: 3$ & $4426: 5$ \\
\hline 30 & $39: 76$ & $30: 47$ & $0: 386$ & $621: 2$ & $3162: 2$ & $4404: 7$ \\
\hline 25 & $41: 23$ & $27: 53$ & $0: 474$ & $486: 0$ & $3400: 3$ & $4372: 3$ \\
\hline 20 & $42: 82$ & $24: 36$ & $0: 569$ & $330: 5$ & $3666: 8$ & $4327: 7$ \\
\hline 15 & $44: 50$ & $21: 00$ & $0: 670$ & $154: 3$ & $3960: 1$ & $4269: 5$ \\
\hline 10 & $46: 27$ & $17: 46$ & $0: 776$ & $\mathrm{i} 42: 7$ & $4281: 5$ & $4196: 1$ \\
\hline
\end{tabular}

Table 2.2: Static Duopoly Market Performance, A Iternative Investigation Thresholds

Note: parameters as for Table 2.1.

\section{Competition Policy and Innovation}

\subsection{M onopoly}

\subsubsection{R acing for cost-saving innovation}

I will use a standard racing model of cost-saving innovation. ${ }^{19}$ I nitially the monopolist produces with unit cost $c_{1}$. By setting up a research project, it can develop a more ed cient technology, reducing unit cost to $c_{2}$ per unit. If it does set up such a research project, the time at which the new technology comes on line is a random variable. The random discovery time I has a Poisson distribution,

$$
\operatorname{Pr}(I \cdot \mathrm{t})=1 \mathrm{i} \text { e } \mathrm{e}^{\mathrm{ht}} ;
$$

where $h$ is the level or intensity of the $R \& D$ project.

The expected time of discovery is the inverse of the $R \& D$ intensity,

$$
E(I)=\frac{1}{h}
$$

\footnotetext{
${ }^{19} \mathrm{~B}$ ecause the basic model is well known, I give it an abbreviated treatment. For further discussion, see Reinganum (1989) or the Appendix to Martin (1997).
} 
A greater level of $R \& D$ activity therefore brings forward the expected time of discovery.

A greater level of $R \& D$ activity is also more costly: the $R \& D$ cost function is $z(h)$, with positive and increasing marginal cost of $R \& D$ exort:

$$
z^{9}(h)>0 \quad z^{\oplus}(h)>0:
$$

The expected present discounted value of the monopolist is

$V_{m}={ }_{t=0}^{Z_{1}} e^{i(r+h) t}{ }^{1 / 4 m}\left(c_{1} ; g\right) i z(h)+\frac{h^{1 / 4 m}\left(c_{2} ; g\right)}{r} d t=\frac{1 / 4 m\left(c_{1} ; g\right) i z(h)+\frac{h^{1 / m}\left(c_{2} ; g\right)}{r}}{r+h}$

where

$$
\begin{aligned}
& 1 / 4_{n}\left(C_{1} ; g\right)=\text { instantaneous preinnovation payox } \\
& 1 / 4_{n}\left(C_{2} ; g\right)=\text { instantaneous post-innovation payox }
\end{aligned}
$$

and $c_{2}<c_{1}$ implies that the payox is greater after innovation:

$$
1 / 4 n\left(C_{2} ; g\right)>1 / 4 n\left(c_{1} ; g\right):
$$

The ..rst-order condition to maximize $\mathrm{V}_{\mathrm{m}} \mathrm{is}^{20}$

$$
\begin{aligned}
& \frac{@ V_{m}}{@ h}=\frac{(r+h) \frac{h_{1 / m n}\left(c_{2} ; g\right)}{r} i z^{q}(h)^{i} i^{h}{ }^{h / m}\left(c_{1} ; g\right) ; z(h)+\frac{h^{1 / m}\left(c_{2} ; g\right)}{r}}{(r+h)^{2}} \\
& =\frac{\left.1 / 4_{n}\left(c_{2} ; g\right) ; 1 / 4_{n}\left(c_{1} ; g\right)+z(h) i(r+h) z^{q} h\right)}{(r+h)^{2}}=0 \text { : }
\end{aligned}
$$

\subsubsection{Comparative statics with respect to $g$}

Dixerentiate the numerator of (3.8) with respect to $\mathrm{g}$ and rearrange terms to obtain

$$
\frac{d h}{d g}=\frac{1}{(r+h) z^{G}(h)} \frac{\left.@ 1 / 4 m\left(c_{2} ; g\right) ; 1 / 4 n\left(c_{1} ; g\right)\right]}{@ g}
$$

In view (3.3), the comparative static derivative has the same sign as the derivative of the pro..t increment,

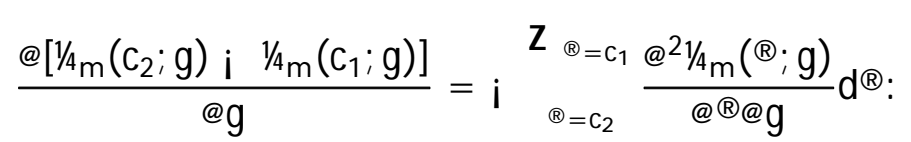

\footnotetext{
${ }^{20} \mathrm{~T}$ he assumption that $z^{\infty}>0$ is suф cient to ensure that the ..rst-order condition identi..es a maximum.
} 


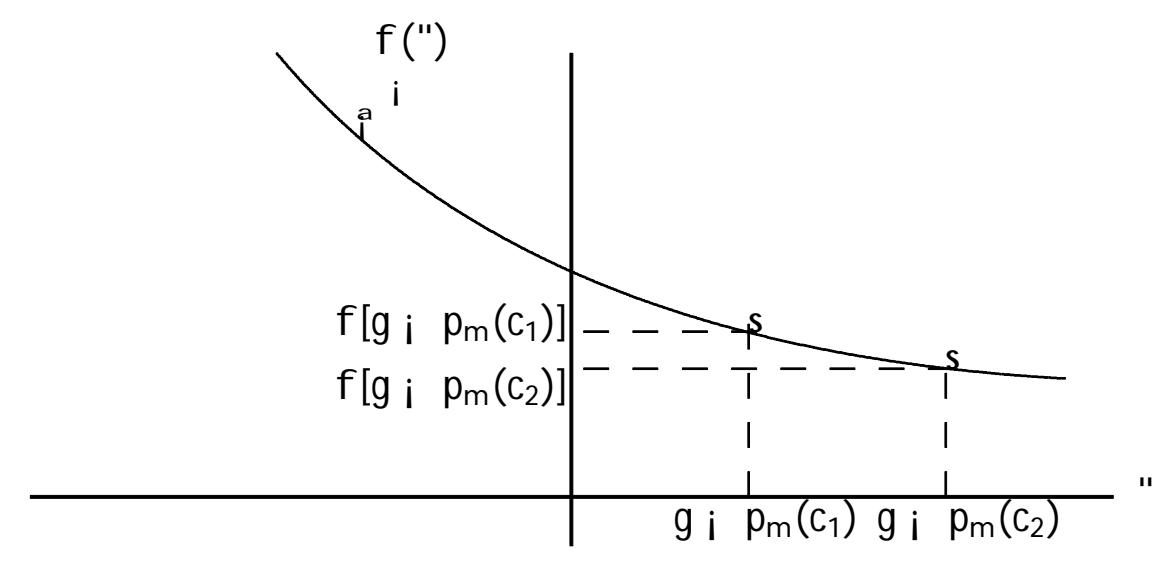

Figure 3.1: Equilibrium $g$ i $p\left(c_{i}\right)$

A suф cient condition for $\mathrm{dh}=\mathrm{dg}<0$ is that

$$
\frac{@^{2} 1 / 4 n(c ; g)}{@ c @ g}>0 \text { : }
$$

To interpret this condition, write

$$
\frac{@^{21} 1 / 4 n(c ; g)}{@ c @ g}=\frac{@}{@ c} \frac{\tilde{A}}{d 1 / 4 n} \text { ! }
$$

and recall from (2.14) $d^{1} / 4 m=d g>0$.

If condition (3.11) holds, then innovation, which reduces unit cost, reduces the impact of a reduction in $\mathrm{g}$ on the ..rm's pro..t. ${ }^{21}$ In other words, if (3.11) holds, one incentive for the ..rm to innovate is to shield itself from the threat of antitrust ..nes.

Using (2.14) to evaluate (3.10),

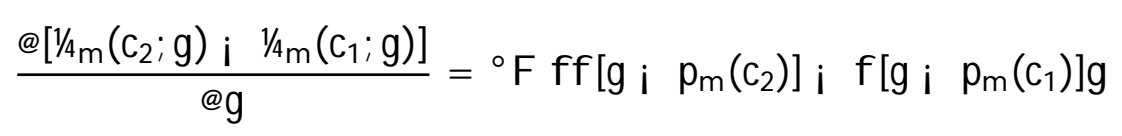

\footnotetext{
${ }^{21}$ The analogy with strategic substitutability is clear. Note that (1) Bulow et al (1985) normalize variables so that greater values indicate more aggressive play, while here lower values of $\mathrm{g}$ indicate more aggressive monitoring by the competition authority and lower values of $\mathrm{c}$ imply greater output; and (2) c is not a choice variable of the ..rm.
} 
(3.13) is negative, as shown in Figure 3.1. The lower cost that follows successful innovation implies a lower monopoly price, leading to

$$
\begin{gathered}
0<p_{m}\left(c_{2}\right)<p_{m}\left(c_{1}\right) \\
g_{i} p_{m}\left(c_{2}\right)>g \text { i } p_{m}\left(c_{1}\right) \\
0<f\left[g_{i} p_{m}\left(c_{2}\right)\right]<f\left[g_{i} p_{m}\left(c_{1}\right)\right]:
\end{gathered}
$$

Consequently

$$
\frac{\mathrm{dh}}{\mathrm{dg}}<0:
$$

This gives the ..rst result of the model:

Theorem 1: Stricter product-market competition policy increases monopoly equilibrium $R \& D$ intensity.

A tougher competition policy compresses the incumbent's pre- and post-innovation payoxs. But it compresses the incumbent's pre-innovation payoo more than the incumbent's post-innovation payox, resulting in greater $R \& D$ exort and (in view of (3.2)), a shorter expected time to discovery.

Figure 3.2 illustrates this result for the linear demand example underlying Table 2.1 and the demand uncertainty density shown in Figure 2.1. The innovation is moderate: unit cost after production is 5 rather than 10; the interest rate is $10 \%$. The $R \& D$ cost function is quadratic,

$$
z(h)=u h+v h^{2} ;
$$

for $u=10, v=1000$

The curve labeled " $M$ " shows the investigation threshold-expected timetodiscovery relationship. Expected time to discovery is 2.4 time periods without competition policy, 2.3 if $\mathrm{g}=70$, and falls steadily to 1.7 for $\mathrm{g}=10$.

The negative relationship between $g$ and expected discovery time translates into an inverted-U relationship between $g$ and expected present-discounted net social welfare, as shown in Figure 3.3.

Net social welfare is 40,158 without competition policy, 41,402 for $g=70$. Net social welfare rises to 45,428 for $g=20$, then falls to 45,113 for $g=10 .{ }^{22}$

\footnotetext{
${ }^{22} \mathrm{If} \mathrm{g}=10$, the ..rm's instantaneous payou is negative when marginal cost is 10 , positive when marginal cost is 5 , and the ..rm's expected present-discounted value is 2,596.8. This compares with an expected present discounted value of 26,723 without competition policy.
} 


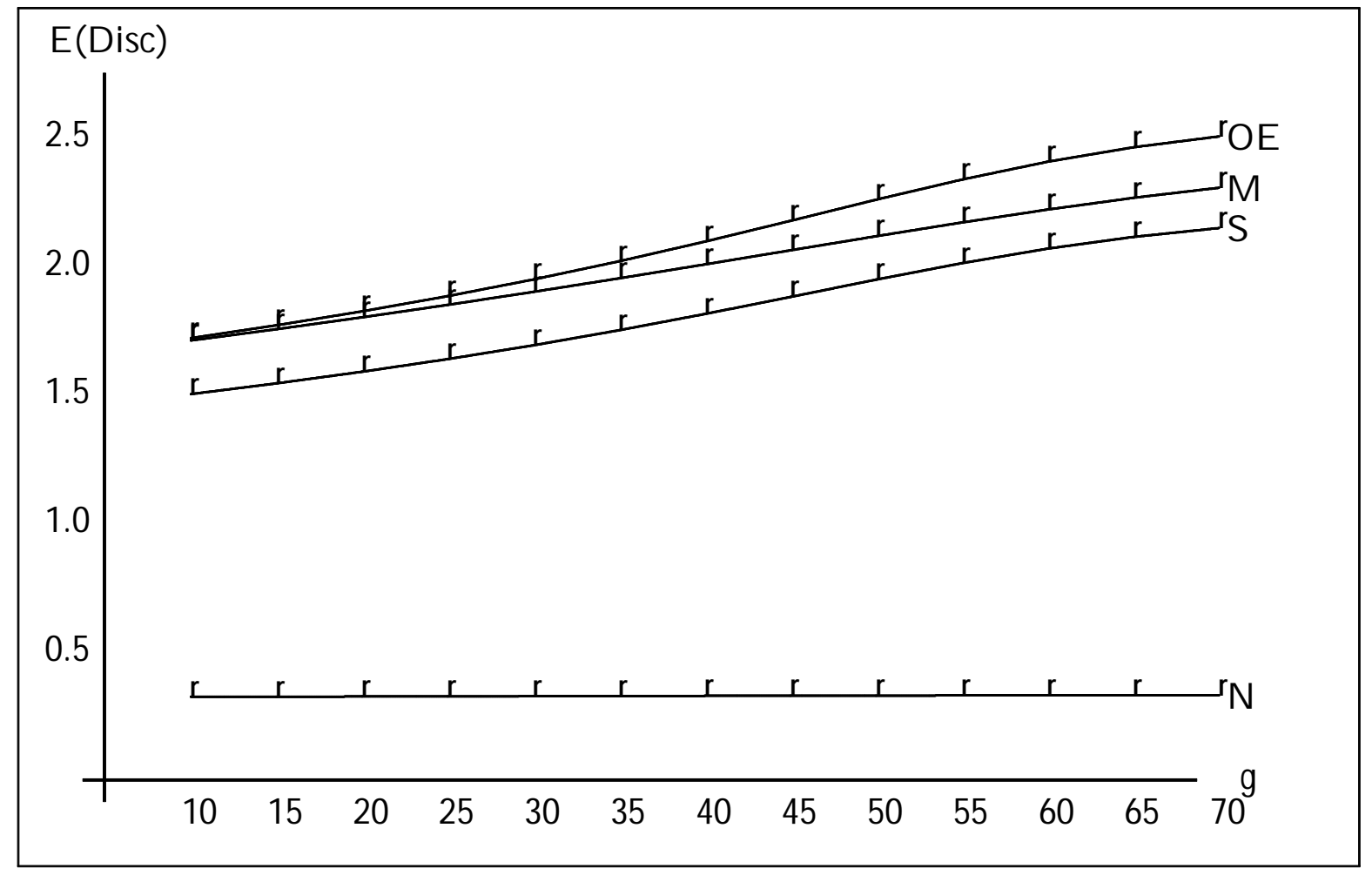

$\mathrm{n}=2, \mathrm{a}=110, \mathrm{c}_{1}=10, \mathrm{c}_{2}=5,3 / 4=10, \mathrm{u}=10, \mathrm{v}=1000, \mathrm{~s}=1$

Figure 3.2: Expected time to discovery, Monopoly and A Iternative Duopoly Cooperation Regimes, $s=1=3$ 


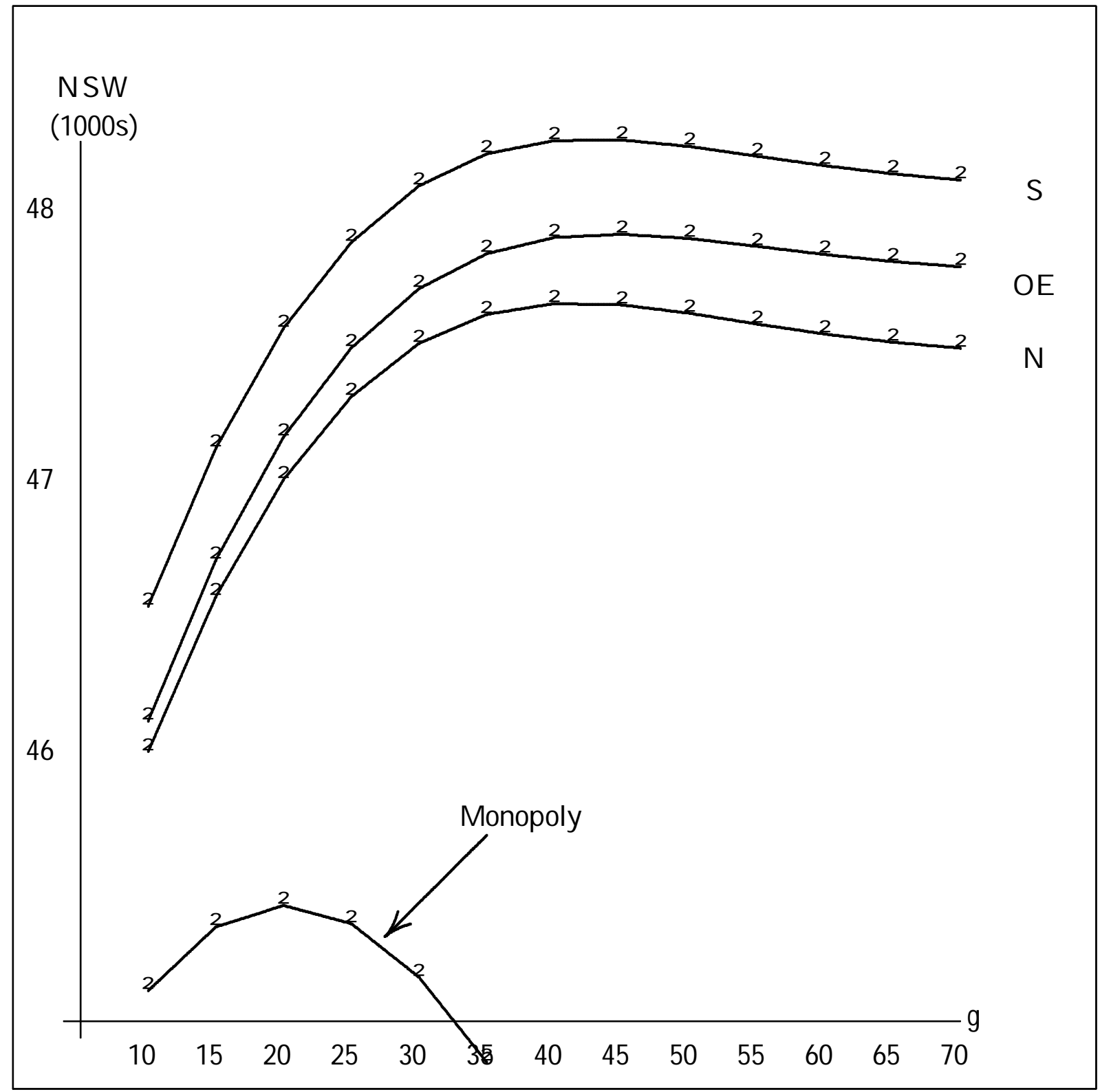

$\mathrm{n}=2, \mathrm{a}=110, \mathrm{c}_{1}=10, \mathrm{c}_{2}=5,3 / 4=10, \mathrm{u}=10, \mathrm{v}=1000, \mathrm{~s}=1 ; \mathrm{N}$ indicates noncooperative $R \& D, O E$ indicates an operating entity joint venture, $S$ indicates a secretariat $R \& D$ joint venture

Figure 3.3: Net social welfare, Alternative $R \& D$ Regimes, $s=1=3$ 


\subsection{Duopoly}

I wish to compare duopoly and oligopoly market performance, allowing for $R \& D$ spillovers and for the possibility of alternative $R \& D$ cooperation arrangements.

\subsubsection{Spillovers}

Each ..rm picks its own $R \& D$ intensity $h_{i}$, interpreted as above. Spillovers inłuence the ..rm's exective $R \& D$ intensity, ${ }^{1}{ }^{\text {i }}$,

$$
{ }^{1}{ }_{i}=h_{i}+s h_{j}
$$

for $\mathrm{i}, \mathrm{j}=1 ; 2$ and $\mathrm{i} \epsilon \mathrm{j}$. The spillover parameter $\mathrm{s}$ lies between zero and one. Zero indicates the absence of spillovers, one indicates that a ..rm's $R \& D$ activity bene..ts its rival as much as itself.

The probability that a ..rm completes its $R \& D$ project at or before time $t$ depends on exective $R \& D$ intensity; the distribution of random discovery time is then

$$
\operatorname{Pr}\left(I_{i} \cdot \mathrm{t}\right)=1_{i} \exp \left(\mathrm{i}^{1}{ }_{\mathrm{i}} \mathrm{t}\right):
$$

Spillovers reduce a ..rm's incentive to spend on $R \& D$, since some of the research exort it pays for bene.ts its rival. However, spillovers increase the exectiveness of such $R \& D$ spending as does take place, since a portion of each ..rm's spending increases the likelihood of discovery of all ..rms.

\subsubsection{N oncooperative $R \& D$}

If the two ..rms carry out independent $R \& D$ projects, the ..rst ..rm to develop the cost-saving process receives an exective patent. In calculating the winning ..rm's post-innovation payoo, I assume that it licenses use of the new technology to the losing ..rm for a fee $c_{1}$ i $c_{2}$ per unit of output. ${ }^{23}$

Let $1 / 4 \mathrm{~N}$ denote the static payo of the .rm that wins the innovation race, $1 / 4$ the static payox of the loser. $1 / \mathrm{N}\left(c_{\mathrm{i}}\right)$ is the static noncooperative Cournot duopoly payox if both ..rms operate with unit cost $\mathrm{c}_{\mathrm{i}}{ }^{24}$

\footnotetext{
${ }^{23}$ I use this speci..cation for its simplicity, not for its realism. It is possible to generalize the model to allow for imperfect post-innovation appropriability. While there is good reason to think that patents do not ensure absolute appropriability, there is also evidence that in many sectors there are other appropriability devices that are exective (Levin et al., 1987).

${ }^{24} \mathrm{~F}$ or notational simplicity, the functional dependence of payoxs on $\mathrm{g}$ is not explicitly noted.
} 
For noncooperative $R \& D, . . r m$ i picks its $R \& D$ intensity $h_{i}$ to maximize its expected present discounted value,

$$
V_{i}^{N}=\frac{1 / N\left(c_{1}\right) i z\left(h_{i}\right)+\frac{{ }^{1}{ }^{1 / / v}+{ }^{1} j^{1 / 4}}{r}}{r+{ }^{1}{ }_{1}+{ }^{1}{ }_{2}}=\frac{1 / N\left(c_{1}\right) i z\left(h_{i}\right)+\frac{\left(1 / v v+s^{1 / 4}\right) h_{i}+\left(s^{1 / / v}+1 / 4\right) h_{j}}{r}}{r+(1+s)\left(h_{1}+h_{2}\right)}
$$

(for $\mathrm{j} \in \mathrm{i})$.

\subsubsection{Operating Entity J oint Venture}

If the two ..rms form an operating entity joint venture, ${ }^{25}$ they carry out one $R \& D$ project and evenly share the cost. The $R \& D$ intensity $h$ of the project is chosen to maximize expected ..rm value,

$$
V_{i}^{O E}=\frac{1 / N\left(C_{1}\right) i \frac{z(h)}{2}+h \frac{1 / N\left(c_{2}\right)}{r}}{r+h}
$$

This assumes that there is noncooperative product-market rivalry before and after innovation.

\subsubsection{Secretariat J oint Venture}

W ith a secretariat joint venture, each ..rm carries out its own $R \& D$ project. $R e-$ sults are shared; when discovery takes place, both ..rms have access to the new technology. The value of a single ..rm is

$V_{i}^{S}=\frac{1 / A N\left(c_{1}\right) i z\left(h_{i}\right)+\left({ }_{1}{ }_{1}+{ }^{1}{ }_{2}\right) \frac{1 / N\left(c_{2}\right)}{r}}{r+{ }^{1}{ }_{1}+{ }^{1}{ }_{2}}=\frac{1 / A N\left(c_{1}\right) i z\left(h_{i}\right)+(1+s)\left(h_{1}+h_{2}\right) \frac{1 / N\left(c_{2}\right)}{r}}{r+(1+s)\left(h_{1}+h_{2}\right)}$

(for $\mathrm{i}=1 ; 2$ ).

\subsubsection{Results}

Theorem 2, which is proven in the A ppendix, outlines the competition policy-R\&D intensity relationship for the alternative $R \& D$ regimes.

Theorem 2: (a) For noncooperative $R \& D$,

$$
\frac{d h_{N}}{d g}=i \frac{1}{D_{1}} \frac{1}{1+s} \frac{d\left(1 / 4 v i \frac{1 / 4}{N}\right)}{d g} \text { is } \frac{d(1 / 4 i 1 / 4)^{\#}}{d g}+(1 ; s) \frac{h}{r} \frac{d(1 / 4 v i 1 / 4)^{\prime}}{d g} ;
$$

\footnotetext{
${ }^{25}$ Vornortas (1994) attributes the terminology "operating entity joint venture" and "secretariat joint venture" to Ouchi (1989).
} 
for

$$
D_{1}=(1 ; s) \frac{1 / 4 v i{ }^{1 / 4}}{r} ; z^{9}(h) i^{\mu} \frac{r}{1+s}+2 h^{9} z^{0}(h)<0
$$

and

$$
\mathrm{dh}_{\mathrm{N}}=\mathrm{dg}<0
$$

for linear demand;

(b) for an operating entity joint venture,

$$
\frac{d h_{O E}}{d g}=\frac{2}{\left(r+h_{O E}\right) z^{\mathbb{C}}\left(h_{O E}\right)} \frac{d\left[1 / 4 N\left(c_{2}\right) i 1 / 4 N\left(c_{1}\right)\right]}{d g} ;
$$

(c) for a secretariat joint venture,

$$
\frac{d h_{S}}{d g}=\frac{3 \quad 1}{z^{q}\left(h_{S}\right)+\frac{r}{1+s}+2 h_{S} z^{\mathscr{C}}\left(h_{S}\right)} \frac{d\left[1 / 4\left(c_{2}\right) ; 1 / 4 N\left(c_{1}\right)\right]}{d g}:
$$

Part (a) shows that for linear demand, stricter competition policy increases noncooperative equilibrium $R \& D$ intensity. For parts (b) and (c), a condition analogous to (3.11) is suф cient for stricter competition policy to increase equilibrium $R \& D$ intensity. As in the monopoly case, if cost reduction reduces the marginal impact of competition policy on the payoxs, then stricter competition policy increases $R \& D$ intensity.

Figure 3.2 illustrates the investigation threshold-expected discovery relationship for linear demand and exponential distribution of ". The spillover rate is $1 / 3$, which is relevant for noncooperative (N) and secretariat (S) $R \& D .{ }^{26}$ Under all three oligopoly regimes, stricter competition policy shortens the expected time to discovery. Noncooperative $R \& D$, with multiple research paths and high $R \& D$ levels, induced by the lure of high payoxs from ..rst success and the threat of low payous otherwise, brings by far the shortest expected discovery time. Expected discovery time with noncooperative $R \& D$ does fall as the threshold price $g$ falls, but the magnitude of the impact is slight. With either type of cooperative $R \& D$, $R \& D$ levels are much lower, and expected time to discovery is much longer than with noncooperative $R \& D$ (and comparable to expected discovery time under monopoly).

The alternative cooperation regimes rank quite dixerently in terms of expected net social welfare (Figure 3.3). Of the three cooperation regimes, secretariat $R \& D$ yields the greatest welfare, independent $R \& D$ the least. Secretariat $R \& D$ dominates operating entity $R \& D$ because two research projects translate into

\footnotetext{
${ }^{26} \mathrm{~T}$ he spillover rate does not axect the outcome for an operating entity joint venture, since with this form of $R \& D$ cooperation there is just one research project.
} 


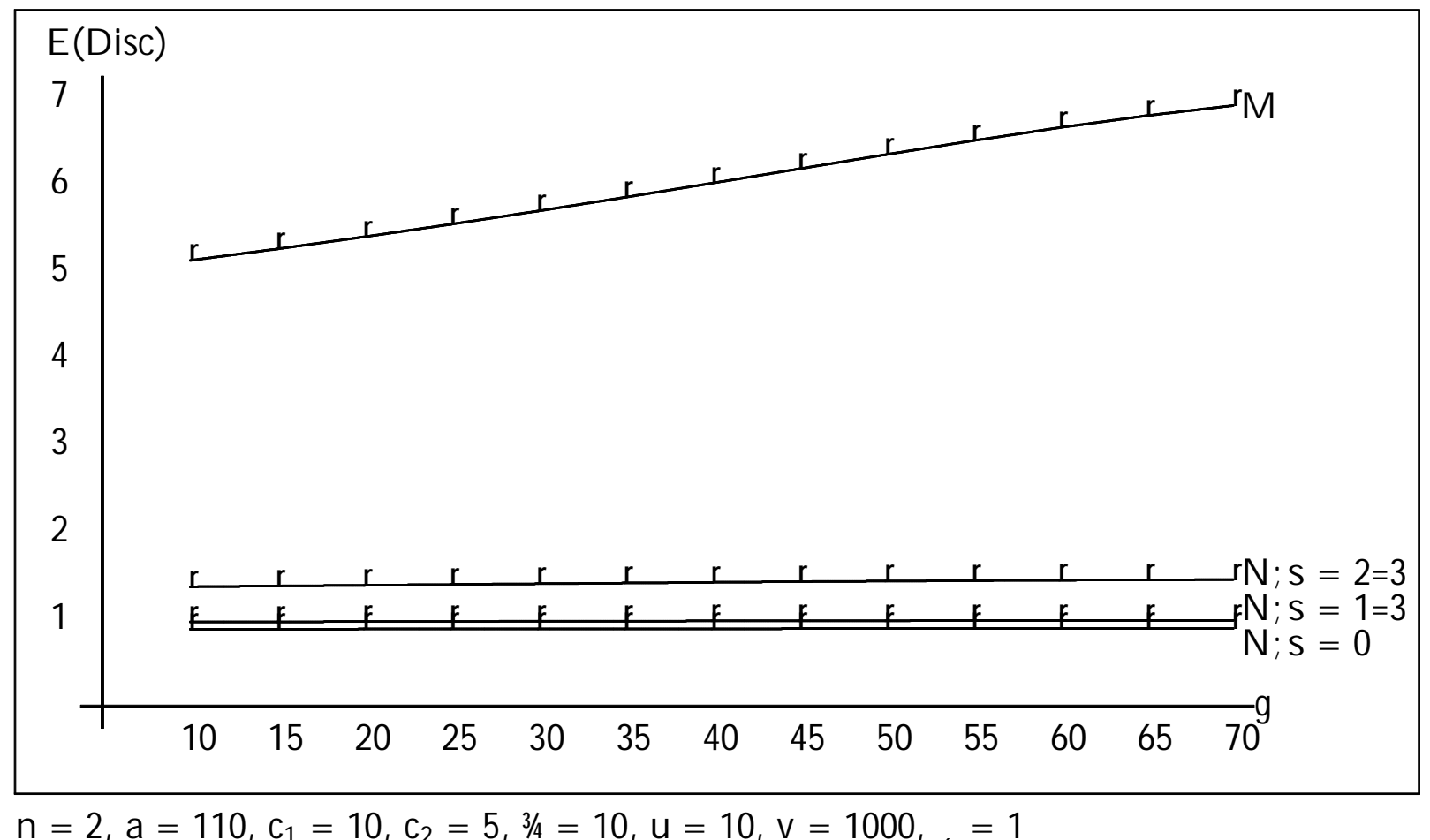

Figure 3.4: Expected time to discovery, Noncooperative $R \& D$, Alternative Spillover Levels

two independent possibilities of bringing the innovation on line. Secretariat and operating entity $R \& D$ both dominate noncooperative $R \& D$ because they imply that both ..rms have access to the new technology after discovery.

All three duopoly cooperation regimes yield greater expected net social welfare than monopoly. For the most part, this rełects better static market performance under duopoly; expected discovery times under monopoly and cooperative $R \& D$ are comparable.

For noncooperative $R \& D$, increases in spillovers increase the expected time to discovery (Figure 3.4), although the magnitude of the exect is slight. Increases in spillovers also increase expected net social welfare (Figure 3.5). Greater spillover levels reduce the single..rm's incentive to spend on $R \& D$, since they make it more likely that the ..rm's $R \& D$ will lead the other ..rm to discovery ..rst. But this also means that such $R \& D$ as does take place is more exective, increasing welfare.

Whether secretariat $R \& D$ or operating entity $R \& D$ yields a shorter expected time to discovery depends on the level of spillovers (F igure 3.6). For low spillover levels, expected discovery time is less with an operating entity $R \& D$. As spillover levels increase, expected discovery time for secretariat $R \& D$ goes down, and be- 


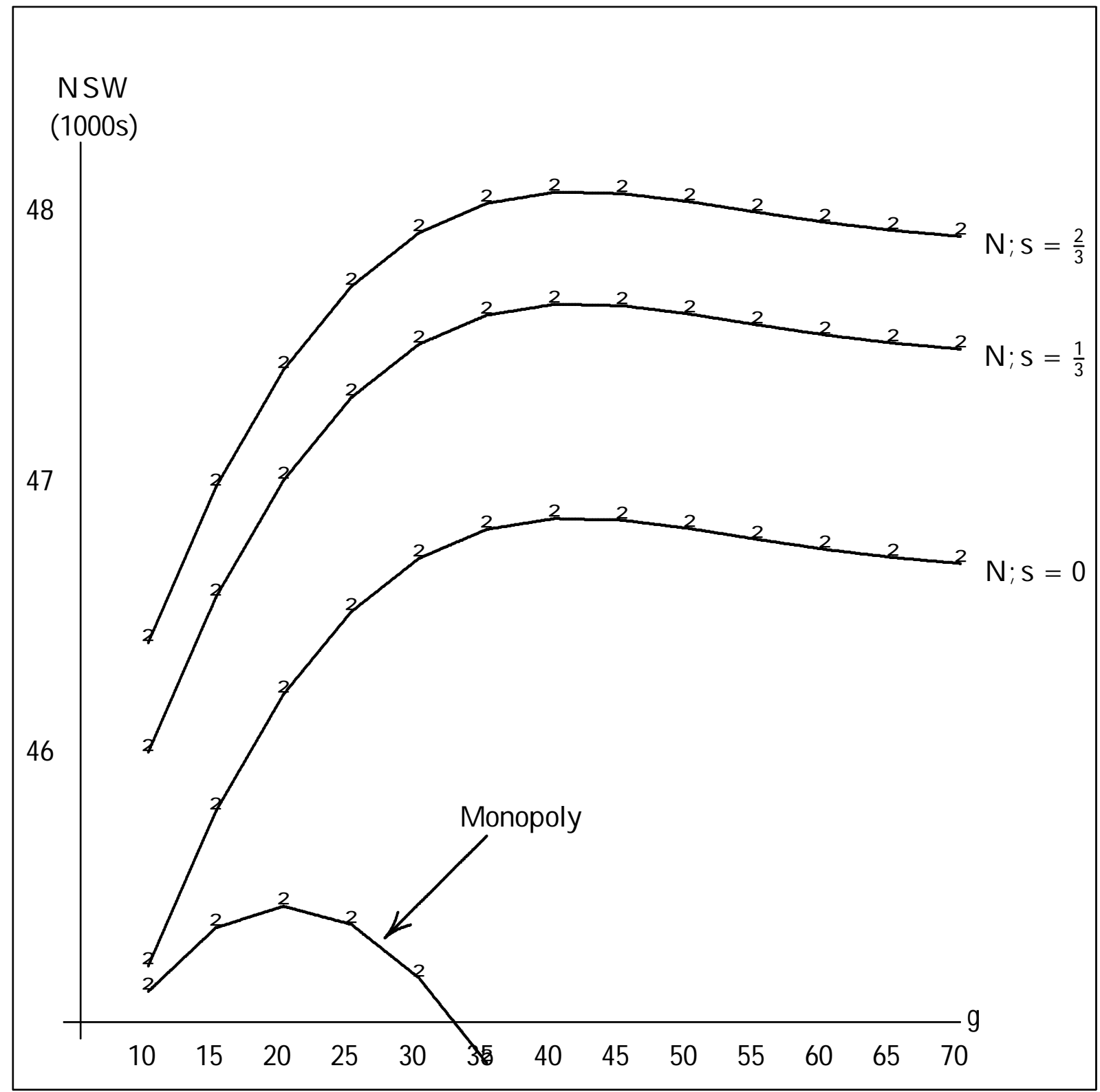

$\mathrm{n}=2, \mathrm{a}=110, \mathrm{c}_{1}=10, \mathrm{c}_{2}=5,3 / 4=10, \mathrm{u}=10, \mathrm{v}=1000, \mathrm{~s}=1 ; \mathrm{N}$ indicates noncooperative $R \& D, O E$ indicates an operating entity joint venture, $S$ indicates a secretariat $R \& D$ joint venture

Figure 3.5: N et social welfare, Noncooperative $R \& D$, A Iternative Spillover Levels 


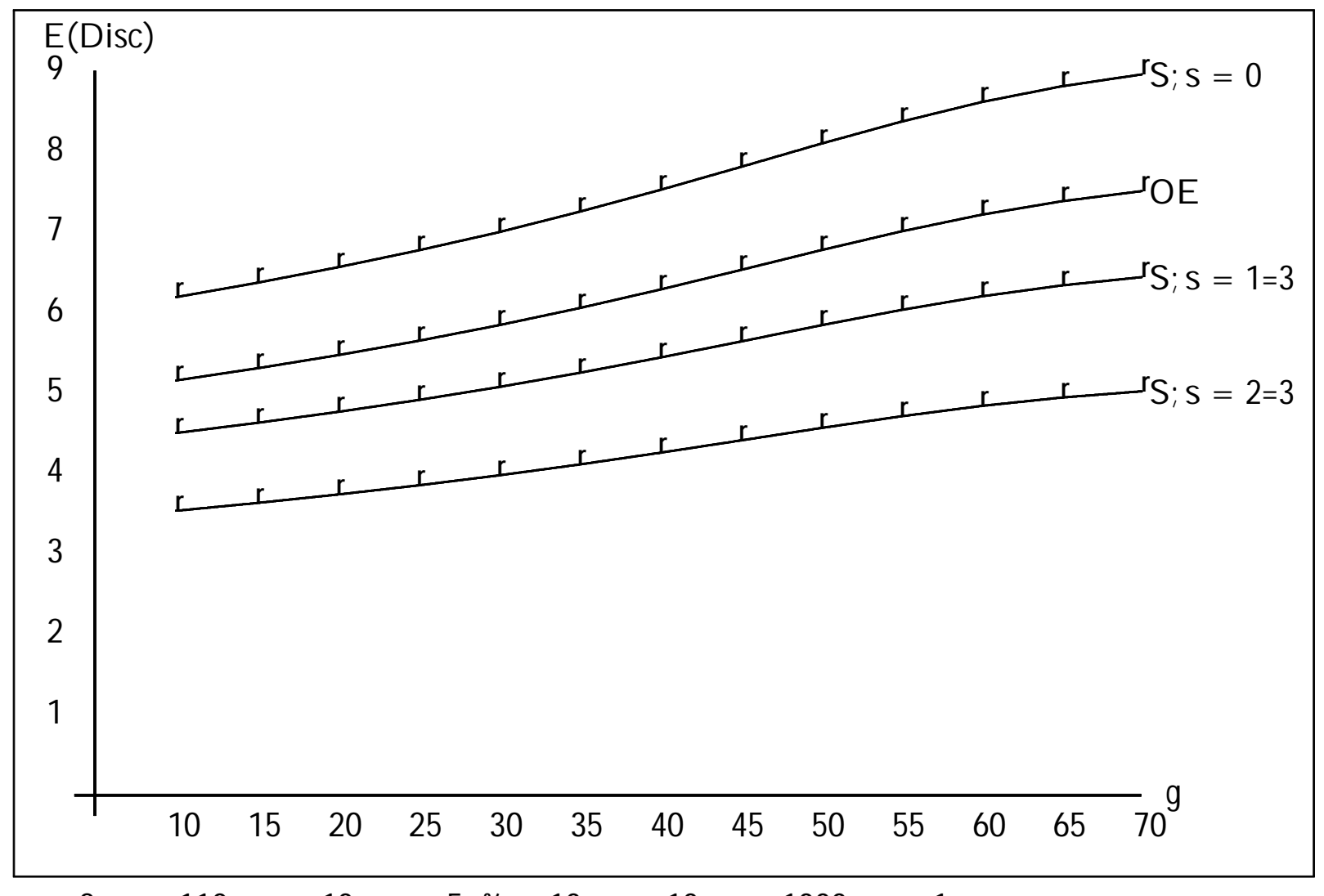

$n=2, a=110, c_{1}=10, c_{2}=5,3 / 4=10, u=10, v=1000,,=1$

Figure 3.6: Expected time to discovery, Cooperative $R \& D$ Regimes, Alternative Spillover Rates

yond a critical level falls below that of operating entity $R \& D$. With secretariat $R \& D$, greater spillovers improve technological performance. This contrasts with noncooperative $R \& D$ (Figure 3.4). The dixerence between the two regimes is that with a secretariat joint venture, all ..rms have equal access to the new technology after innovation.

Secretariat $R \& D$ consistently yields greater expected net social welfare than operating entity $R \& D$ (Figure 3.7). T he welfare level with secretariat $R \& D$ rises with the level of spillovers, as for noncooperative $R \& D$.

\section{Conclusion}

Competition policy reduces expected ..rm pro..ts by exposing ..rms to the possibility of ...nes if they engage in privately pro..table but socially disapproved-of behavior. When enforcement agencies make decisions by monitoring market per- 


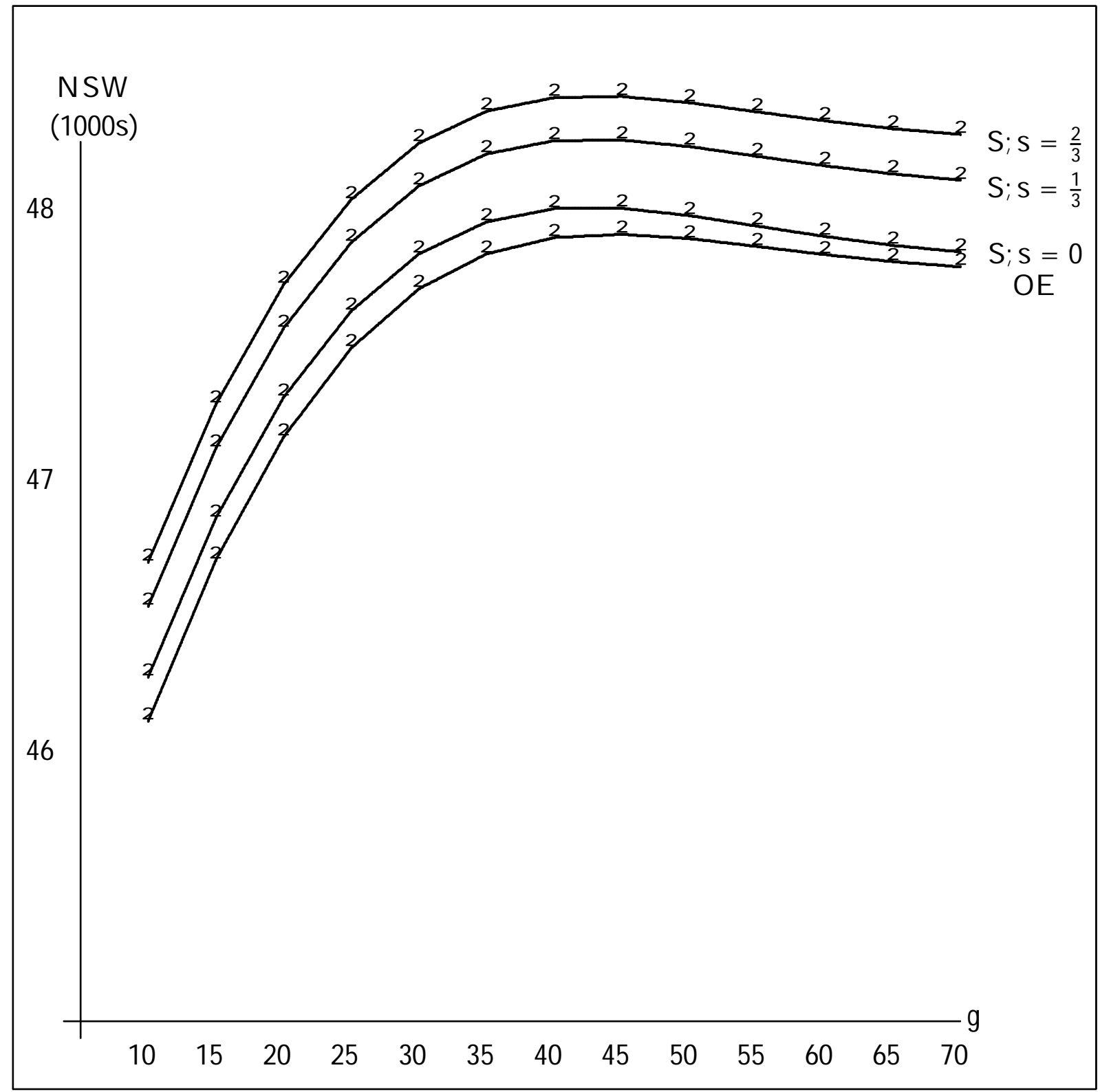

$\mathrm{n}=2, \mathrm{a}=110, \mathrm{c}_{1}=10, \mathrm{c}_{2}=5,3 / 4=10, \mathrm{u}=10, \mathrm{v}=1000,,=1 ; \mathrm{N}$ indicates noncooperative $R \& D, O E$ indicates an operating entity joint venture, $S$ indicates a secretariat $R \& D$ joint venture

Figure 3.7: Net social welfare, Cooperative $R \& D$ Regimes, Alternative spillover levels 
formance, pro..t-maximizing ..rms will expand output, simultaneously reducing the probability of investigation and improving static market performance. They will also increase $R \& D$ exorts, reducing the expected time to development of lower-cost production methods (which will also lower the probability of antitrust prosecution).

There is an inverted-U relationship between competition policy and expected net social welfare. A moderately strict competition policy improves welfare; excessively strict competition policy does not.

Spillovers lower the expected time to discovery for secretariat $R \& D$ and increase it for noncooperative $R \& D$. Spillovers improve net social welfare under both regimes. In the examples considered here, the shortest time to discovery occurs for noncooperative $R \& D$ and zero spillovers. The greatest expected social welfare occurs for secretariat $R \& D$ and high spillover levels. If society wishes to promote technological progress as a goal in and of itself, the recipe suggested by the model developed here is independent $R \& D$ with an exective appropriability mechanism. ${ }^{27}$ If society wishes to promote expected net social welfare, the recipe is secretariat $R \& D$ with spillovers and moderately tough competition policy, which brings multiple $R \& D$ paths, dixusion of results, and improved static market performance.

\section{A ppendix: proof of Theorem 2}

Parts (b) and (c) are immediate from dixerentiation of the respective ..rst-order conditions.

\section{1. $\mathrm{dh}=\mathrm{dg}$}

Firm 1's expected present-discounted value is

$$
v_{1}=\frac{1 / 4 v i z\left(h_{1}\right)+\frac{1}{r}\left[\left(1 / 4 v+s^{1 / 4}\right) h_{1}+\left(s^{1 / 4 v}+1 / 4\right) h_{2}\right]}{r+(1+s)\left(h_{1}+h_{2}\right)}
$$

The ..rst-order condition to maximize $V_{1}$ is

$$
\left[r+(1+s)\left(h_{1}+h_{2}\right)\right]^{2} \frac{@ v_{1}}{\left(h_{1}\right.}=
$$

$1 / 4$ i i $1 / 4$ i s $\left(1 / 4\right.$ i $\left.^{1 / 4}\right)+\left(1_{i} s^{2}\right) \frac{1 / 4 v i \frac{1 / 4}{r}}{r}+(1+s) z\left(h_{1}\right)$ i $\left[r+(1+s)\left(h_{1}+h_{2}\right)\right] z^{9}\left(h_{1}\right)=0$

\footnotetext{
${ }^{27}$ B roadly de..ned, long-lived patents, for example (although it is not clear that there is in fact much government can do to enhance exective appropriability).
} 
The second partial derivative, evaluated along the ..rst-order condition, is

$$
\frac{\varrho^{2} V_{1}}{\oint_{1}^{2}}=i \frac{z^{\mathscr{Q}}\left(h_{1}\right)}{r+(1+s)\left(h_{1}+h_{2}\right)}:
$$

The assumption that $z^{\mathscr{Q}}\left(\mathrm{h}_{1}\right)>0$ is suc cient to ensure that the ..rst-order condition identi..es a maximum.

Dixerentiate the...rst-order condition with respect to $h_{1}$ to obtain an expression for the slope of ..rm 1's $R \& D$ reaction function,

$$
\frac{@ h_{1}}{@ h_{2}}=\frac{1}{z^{\mathbb{Q}\left(h_{1}\right)}} \frac{(1 ; s) \frac{1 / w i^{1 / 2}}{r} ; z^{9}\left(h_{1}\right)}{\frac{r}{1+s}+h_{1}+h_{2}}
$$

Stability requires that this be less than one in absolute value in the neighborhood of equilibrium. Setting $h_{1}=h_{2}=h$, this implies

$$
D_{1}=(1 ; s) \frac{1 / 4 v i \frac{1 / 4}{r}}{r} z^{9}(h) i^{\mu} \frac{r}{1+s}+2 h^{9} z^{\Phi}(h)<0:
$$

This will henceforth be assumed. ${ }^{28}$

Now set $h_{1}=h_{2}=h$ in (5.2) to obtain the equation that determines noncooperative equilibrium $R \& D$ intensity:

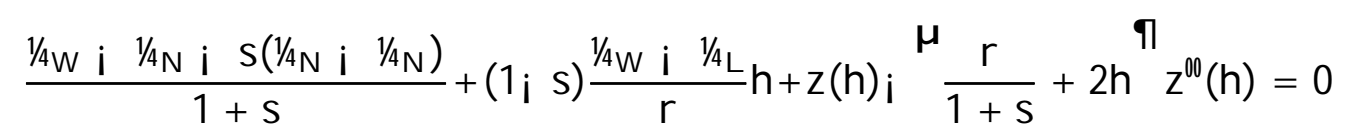

Dixerentiate (5.6) with respect to $g$ to obtain

$$
\frac{d h}{d g}=i \frac{1}{D_{1}} \frac{1}{1+s} \frac{d(1 / 4 v i 1 / 4)}{d g} i s \frac{d\left(1 / 4 i^{1 / 4}\right)^{\#}}{d g}+(1 ; s) \frac{h}{r} \frac{d(1 / 4 v i 1 / 4)^{\prime}}{d g}
$$

In view of (5.5), $d h=d g$ and the term in braces on the right in (5.7) have the same sign. Suф cient conditions for $\mathrm{dh}=\mathrm{dg} \cdot 0$ are

$$
\begin{aligned}
& \frac{d(1 / 4 v i 1 / 4 N)}{d g} \cdot 0 \\
& \frac{d(1 / 4 N i 1 / 4)}{d g}, 0 \\
& \frac{d(1 / 4 v i 1 / 4)}{d g} \cdot 0
\end{aligned}
$$

\footnotetext{
${ }^{28}$ Stability conditions were satis..ed for the simulations reported in the text.
} 
5.2. Comparative statics, post-innovation market

First evaluate (5.10). I assume that demand is linear. Payoxs are

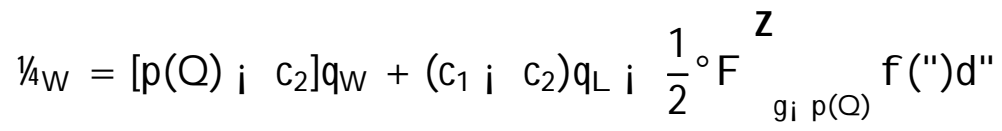

$$
\begin{aligned}
& 1 / 4=\left[p(Q) \text { i } c_{2}\right] q_{L} \quad i \frac{1}{2}^{\circ} F^{Z}{ }_{g i p(Q)}^{Z} f(") d^{\prime \prime} ;
\end{aligned}
$$

where

$$
\mathrm{Q}=\mathrm{qw}_{\mathrm{w}}+\mathrm{qL}_{\mathrm{L}}
$$

is noncooperative equilibrium output in the post-innovation market.

The ..rst-order conditions for pro..t maximization are

$$
\begin{aligned}
& \frac{@ /{ }_{N}}{@_{w}}=p(Q) ; \quad c_{2}+q_{w} p^{0} ; \frac{1}{2}^{\circ} F f p^{0}=0 \\
& \frac{@ / 4}{@_{L}}=p(Q) ; c_{1}+q_{L} p^{0} ; \quad \frac{1}{2}^{\circ} F f p^{0}=0
\end{aligned}
$$

Note that (5.14) and (5.15) imply

$$
q_{w} i \frac{1}{2}^{\circ} F f=i \frac{p_{i} c_{2}}{p^{0}}>0
$$

and

$$
q_{L} i \frac{1}{2}^{\circ} F f=i \frac{p_{i} c_{1}}{p^{0}}>0
$$

respectively.

Dixerentiate $1 / 4 v$ and $1 / 4$ with respect to $g$ to obtain:

$$
\begin{aligned}
& \frac{d^{1} / 4 v}{d g}=\frac{@ / 4 v}{@ q_{w}} \frac{d q_{W}}{d g}+\frac{@ / 4 v}{@ q_{L}} \frac{d q_{L}}{d g}+\frac{@ / 4 v}{@ g} \\
& \frac{d^{1} / 4}{d g}=\frac{@ / 4}{@ q_{w}} \frac{d q_{W}}{d g}+\frac{@ / 4}{@ q_{L}} \frac{d q_{L}}{d g}+\frac{@ / 4}{@ g}
\end{aligned}
$$

(5.14) makes the ..rst term on the right in (5.18) equal to zero; (5.15) makes the second term on the right in (5.19) equal to zero; this is the envelope theorem. By inspection, (5.11) and (5.12) imply

$$
\frac{@ / 4 N}{@ 9}=\frac{@ / 4}{@ 9}:
$$


Hence

$$
\frac{d(1 / 4 v ; 1 / 4)}{d g}=\frac{@ / 4 v}{@ q_{L}} \frac{d q_{L}}{d g} ; \frac{@ / 4 / 4}{@_{w}} \frac{d q_{w}}{d g}:
$$

Dixerentiate (5.11) with respect to $q_{L}$ :

$$
\begin{gathered}
\frac{@ / / 4 w}{@ q_{L}}=p^{0} q_{w}+c_{1} i c_{2} i \frac{1}{2}^{\circ} F f p^{0} \\
=p^{0} q_{w} i \frac{1}{2}{ }^{\circ} \mathrm{F}+c_{1} i c_{2} \\
=p^{0} i \frac{p_{i} c_{2}}{p^{0}}+c_{1} i c_{2} \\
=i\left(p ; c_{1}\right)
\end{gathered}
$$

(using (5.16)).

Dixerentiate (5.12) with respect to $q_{w}$ :

$$
\frac{@ / 4}{@_{w}}=p^{0} q_{L} \text { i } \frac{1}{2}^{\circ} \mathrm{F} f p^{0}=i\left(p ; c_{1}\right)
$$

(using (5.17)).

Substitute (5.22) and (5.23) into (5.21) to obtain

$$
\frac{d\left(1 / 4 v i \frac{1 / 4}{4}\right)}{d g}=\left(\begin{array}{ll}
p_{i} & c_{1}
\end{array}\right) \frac{\tilde{A}}{d g} ; \frac{d q_{L}}{d g} \text { : }
$$

Now subtract (5.15) from (5.14) and rearrange terms to obtain

$$
q_{w} \text { i } q_{L}=i \frac{c_{1} i c_{2}}{p^{0}}>0 \text { : }
$$

This implies

$$
\frac{d\left(q_{w} \text { i } q_{L}\right)}{d g}=0 \text { : }
$$

Hence

$$
\frac{d\left(1 / 4 v i \frac{1 / 4}{4}\right)}{d g}=0
$$

and (5.10) is satis.ed. 


\subsection{Comparative statics, pre-innovation market}

Now turn to consideration of (5.8) and (5.9).

If both ..rms operate with unit cost $c_{1}, . . r m$ 1's payox is

$$
1 / \mathbb{A}=\left[p\left(q_{1}+q_{2}\right) ; c_{1}\right] q_{1} \text { i } \frac{1}{2}^{\circ} F^{z} \underset{g_{i} p\left(q_{1}+q_{2}\right)}{z} f(") d^{\prime \prime}
$$

Equilibrium per-..rm output $\mathrm{q}_{\mathbb{N}}$ satis..es the condensed ..rst-order condition

$$
p\left(2 q_{N}\right) ; c_{1}+p^{0} q_{N} i \frac{1}{2}^{\circ} F f^{q}=0
$$

This implies

$$
q_{N} i \frac{1}{2}^{\circ} F f=i \frac{p\left(2 q_{N}\right) ; c_{1}}{p^{0}}>0 \text { : }
$$

Dixerentiating (5.29) with respect to $\mathrm{q}_{\mathbb{N}}$ gives the comparative static derivative

$$
\frac{d q_{N}}{d g}=\frac{1}{2} \frac{{ }^{\circ} F f^{0}}{3+p^{\infty} F f^{0}}=\frac{1}{2} \frac{1}{p^{0}+\frac{3}{{ }^{\circ} F^{0}}}<0:
$$

The indicated sign depends on $f 9 g ; p)<0$, which is henceforth assumed.

Firm 1's equilibrium payou is

$$
1 / A_{N}=\left[\begin{array}{lll}
p\left(2 q_{N}\right) ; & c_{1}
\end{array}\right] q_{N} i_{i^{2}}{ }^{\circ} F^{Z}{\text { gi } p\left(2 q_{N}\right)}^{Z} f(") d^{\prime \prime}
$$

Dixerentiate (5.32) with respect to g:

$$
\frac{d^{1 / 4 N}}{d g}=\frac{d^{1 / 4 N}}{d q_{N}} \frac{d q_{N}}{d g}+\frac{@ g / / N}{@ g}
$$

To evaluate $d^{1 / 4} /{ }_{N}=d q_{N}$, dixerentiate (5.32) with respect to $q_{N}$ :

$$
\begin{aligned}
& \frac{d^{1 / / N}}{d q_{N}}=p ; \quad c_{1}+2 q_{N} p^{0} ;{ }^{\circ} F f p^{0} \\
= & q_{N} ; \frac{1}{2}^{\circ} F \quad p^{0}=i\left[p\left(2 q_{N}\right) ; c_{1}\right]
\end{aligned}
$$

Subtract (5.33) from (5.18):

$$
\frac{d\left(1 / 4 v i^{1 / 4 N}\right)}{d g}=\frac{@ / 4 v}{@ q_{L}} \frac{d q_{L}}{d g} ; \frac{d^{1 / 4 N}}{d q_{N}} \frac{d q_{N}}{d g}+\frac{\left.\oint^{1 / 4 N} i^{1 / 4 N}\right)}{@ g}
$$

First consider the ..nal term: 


$$
\begin{aligned}
& \frac{@ / 4 N}{@ g}=\frac{1}{2}^{\circ} F f[g i p(Q)] \\
& \frac{@ / 4 N}{@ g}=\frac{1}{2}^{\circ} F f\left[g i p\left(2 q_{N}\right)\right]
\end{aligned}
$$

Since

$$
\begin{aligned}
& \text { Q }>2 q_{N} \\
& p(Q)<p\left(2 q_{N}\right) \\
& g_{\text {i }} p(Q)>g_{\text {i }} p\left(2 q_{N}\right) \\
& f\left[g_{i} p(Q)\right]<f\left[g_{i} p\left(2 q_{N}\right)\right]
\end{aligned}
$$

and ..nally

$$
0<\frac{@ / 4 v}{@}<\frac{@ / 4}{@}
$$

or

$$
\frac{\left(9^{1 / 4 v i 1 / 4 N}\right)}{@ g}<0 \text {; }
$$

the ..nal term on the right in (5.35) is negative.

Now turn to

$$
\begin{gathered}
\frac{@ / 4_{N}}{q_{L}} \frac{d q_{L}}{d g} ; \frac{d 1 / N_{N}}{d q_{N}} \frac{d q_{N}}{d g} \\
=i\left[p(Q) ; c_{1}\right] \frac{d q_{L}}{d g}+\left[p\left(2 q_{N}\right) ; c_{1}\right] \frac{d q_{N}}{d g} \\
=\frac{p\left(2 q_{N}\right) ; c_{1}}{\frac{3}{f \circ\left[g_{i}\left(2 q_{N}\right)\right]}+{ }^{\circ} F p^{0}} ; \frac{p(Q) ; c_{1}}{\frac{3}{f 0[g i p(Q)]}+{ }^{\circ} F p^{0}}
\end{gathered}
$$

A ssume that $f^{0}<0, f{ }^{\oplus}>0$ over the range of "that is relevant for the preand post-innovation equilibria. This is a regularity condition on the distribution of the random part of demand.

Then

$$
\left.\left.f q g_{i} p\left(2 q_{N}\right)\right]<f q_{i} \quad p(Q)\right]<0
$$

(see Figure 5.1);

$$
\begin{aligned}
& \left.\left.{ }^{\circ} \mathrm{Ff} q \mathrm{~g}_{\mathrm{i}} \mathrm{p}\left(2 \mathrm{q}_{\mathrm{N}}\right)\right]<{ }^{\circ} \mathrm{Ff} q \mathrm{~g}_{\mathrm{i}} \mathrm{p}(\mathrm{Q})\right]<0 \\
& \frac{3}{\left.{ }^{o} F f g_{i} p(Q)\right]}<\frac{3}{\left.{ }^{o} F f g_{i} p\left(2 q_{N}\right)\right]}<0
\end{aligned}
$$




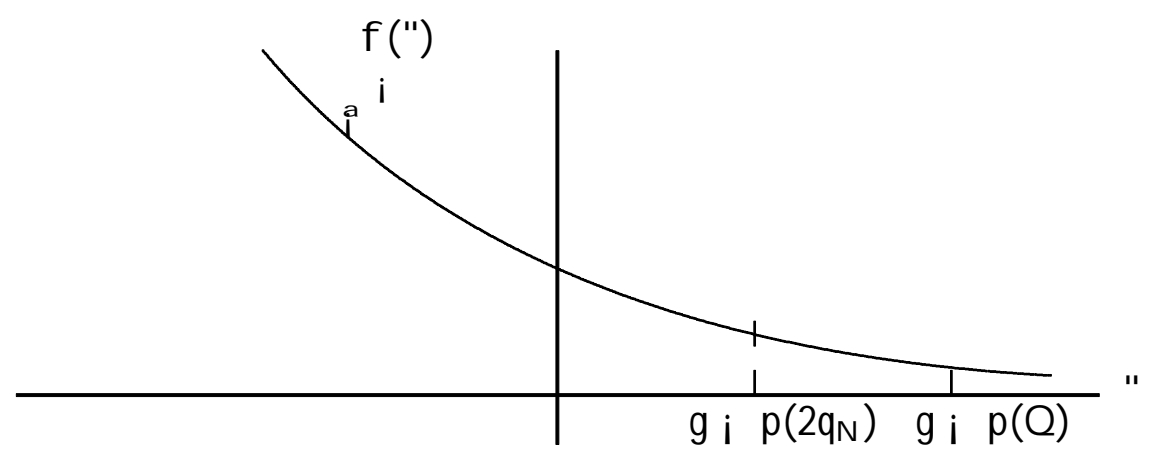

Figure 5.1: Equilibrium $g$ i $p\left(2 q_{N}\right), g$ i $p(Q)$

$$
\begin{aligned}
& p^{0}+\frac{3}{\left.{ }^{\circ} F f q g i p(Q)\right]}<p^{0}+\frac{3}{\left.{ }^{0} F f q g i p\left(2 q_{N}\right)\right]}<0 \\
& \frac{1}{p^{0}+\frac{3}{{ }^{\circ} F f\left[g i p\left(2 q_{N}\right)\right]}}<\frac{1}{p^{0}+\frac{3}{{ }^{\circ} F f[g i p(Q)]}}<0
\end{aligned}
$$

Combining (5.49) and (5.39) gives

$$
\frac{p\left(2 q_{N}\right) i c_{1}}{p^{0}+\frac{3}{{ }^{F} F f 0\left[g_{i} p\left(2 q_{N}\right)\right]}}<\frac{p(Q) i c_{1}}{p^{0}+\frac{3}{{ }^{\circ} F f[g i p(Q)]}}<0
$$

Hence

$$
\frac{@ 1 / 4 N}{q_{L}} \frac{d q_{L}}{d g} ; \frac{d^{1} / N_{N}}{d q_{N}} \frac{d q_{N}}{d g}<0:
$$

Combined with (5.43), this establishes that (5.8) is satis..ed.

Essentially the same arguments, with appropriate sign changes, show that (5.9) is satis..ed. This establishes part (a) of Theorem 2. 


\section{R eferences}

A rrow, K enneth J . "E conomic W elfare and the Allocation of R esources for Invention," in The Rate and Direction of Inventive Activity: E conomic and Social Factors, NBER, Princeton: Princeton University Press, 1962, pp. 609-625.

B esanko, D. and Spulber, D. "Antitrust enforcement under asymmetric information," E conomic J ournal Volume 99, J une 1989, pp. 408-25.

Bulow, J eremy I., Geanakoplos, J ohn D., and Klemperer, Paul D. "Multimarket oligopoly: strategic substitutes and complements," J ournal of Political Economy Volume 93, Number 3, 1985, pp. 488-511.

Gilbert, Richard J. and Newbery, David M. G. "Preemptive patenting and the persistence of monopoly," American E conomic Review Volume 72, Number 3, J une 1982, pp. 514-26.

- "Uncertain innovation and the persistence of monopoly: comment," American E conomic Review Volume 74, Number 1, March 1984, pp. 238-242.

Grossack, Irvin M. "OPEC and the antitrust laws," J ournal of E conomic I ssues Volume 20, Number 3, September 1986, pp. 725-41.

J orde, Thomas M. and Teece, David J. "Harmonizing competition policy in regimes of rapid technological change," in Leonard Waverman, W illiam S. Comanor, and Akira Goto, editors. Competition Policy in the Global Economy. London and New York: Routledge, 1997.

Levin, Richard C., Klevorick, A. K., Nelson, R. R. and W inter, S. G. "A ppropriating the returns from industrial research and development," Brookings Papers on Economic Activity Microeconomics 1987, pp. 783-820.

Martin, Stephen "R\&D J oint Ventures and Tacit Product Market Collusion," European J ournal of Political Economy, Volume 11, Number 4, A pril 1996, pp. 733-741.

- "Public policies towards cooperation in research and development," in Leonard Waverman, W illiam S. Comanor, and A kira G oto, editors. Competition Policy in the Global Economy. London and New York: Routledge, 1997.

- "Competition policy: publicity vs. prohibition \& punishment," forthcoming in Stephen Martin, editor, European Competition Policies. Elsevier-North Holland Publishers, 1998. 
Meißner, Werner and Markl, Rainer "International R\&D cooperations," in Leonard Waverman, W illiam S. Comanor, and A kira G oto, editors. Competition Policy in the Global Economy. London and New York: Routledge, 1997.

Ouchi, W. G. "The new joint $R \& D$, , Proceedings of the IEEE Volume 77, no. 9, 1989, pp. 1318-1326.

Priest, George "The common law process and the selection of ec cient rules," J ournal of Legal Studies Volume 6, Number 1, J anuary 1977, pp. 65-82.

Reinganum, J ennifer $F$. "Uncertain innovation and the persistence of monopoly," American Economic Review Volume 73, Number 4, September 1983, pp. 741-8.

- "The timing of innovation: research, development, and dixusion," in Richard Schmalensee and Robert D. Willig, editors, Handbook of Industrial Organization. A msterdam: North-Holland, 1989, Volume 1, pp. 849-908.

Rubin, Paul H. "Why is the common law et cient?," J ournal of Legal Studies Volume 6, Number 1, J anuary 1977, pp. 51-63.

Suzumura, Kotaro and Goto, Akira "Collaborative $R \& D$ and competition policy," in Leonard Waverman, William S. Comanor, and A kira Goto, editors. Competition Policy in the Global E conomy. London and New York: Routledge, 1997.

Vonortas, Nicholas S. "Inter-..rm cooperation with imperfectly appropriable research," International J ournal of Industrial Organization Volume 12, Number 3, September 1994, pp. 413-35. 